\title{
PATIENTS' KNOWLEDGE TOWARDS PREVENTION OF COMPLICATIONS FROM HYPERTENSION AFTER HEALTH EDUCATION INTERVENTION IN NGHE AN FRIENDSHIP GENERAL HOSPITAL: A QUASI-EXPERIMENTAL STUDY
}

\author{
Ngo Huy Hoang ${ }^{1}$, Nguyen Thi Huong ${ }^{2}$, Nguyen Van Tuan ${ }^{2}$ \\ Lê Thi Huyen Trinh ${ }^{1}$, Nguyen Ngoc Thanh', Hoang Thi Kim Yen ${ }^{3}$ \\ ${ }^{1}$ Nam Dinh University of Nursing; ${ }^{2}$ Vinh Medical University; \\ ${ }^{3}$ Nam Dinh Provicial General Hospital
}

\begin{abstract}
Objective: To describe the current knowledge towards prevention hypertensive complications among outpatients managed by Nghe An Friendship General Hospital Hospital in 2021 and to evaluate changes in their knowledge regarding prevention complications from hypertension after a health education intervention. Method: A before and after study design was conducted in 89 hypertensive outpatients managed by Nghe An Friendship General Hospital from February to April 2021. The patients' knowledge towards the prevention of hypertensive complications was carried out before, right after and one month after the intervention. Results: The overall mean $\pm S D$ score of study patients' knowledge in preventing hypertensive complications before the intervention was unsatisfactory with $30.28 \pm 4.63$ per the total 56 points of the scale. There was a significant improvement right after the intervention as well as one month after the intervention with $55.30 \pm 4.36$ and $52.89 \pm 5.37$, respectively ( $p$ values of 0.001$)$. Conclusion: The education intervention improved significantly the study patients' knowledge on preventing complications from hypertension. The study's results show the need to enhance patients' knowledge towards preventing complications for hypertensive outpatients.
\end{abstract}

Keywords: Hypertension, preventing complications, health education.

\section{INTRODUCTION}

According to the World Health Organization, hypertension or high blood pressure is a major health problem worldwide that increases significantly the risks of heart, brain, kidney and other diseases. There were estimated 1.28 billion adults aged $30-79$ years worldwide have hypertension, the most (two-thirds) of them are living in low-and middle-income countries, $46 \%$ of adults with hypertension are unaware that they have the condition, less than half of adults (42\%) with hypertension are diagnosed and treated, approximately 1 in 5 adult persons (21\%) with hypertension have it under control. In fact, hypertension is a major cause of premature death worldwide and one of the global targets for non-communicable diseases is to reduce the prevalence of hypertension by $33 \%$ between 2010 and
Cor. author: Ngo Huy Hoang

Address: Nam Dinh University of Nursing Email: ngohoang64@ndun.edu.vn
Received: Feb 10, 2022

Accepted: Mar 01, 2022

Published: Mar 02, 2022 
2030 [1]. Hypertension has long been recognized as a serious medical condition that is estimated to cause more than $13 \%$ of deaths annually. Firstly, it is a multifactorial clinical condition characterised by high and sustained levels of blood pressure. Secondly, it is one of the most important public health problems in the world and an important modifiable risk factor for the development of cardiovascular diseases. High blood pressure is associated with high risk for development of heart disease, stroke, chronic kidney disease, retinopathy and peripheral vascular disease [2].

Literature reviews indicated that adoption of healthy lifestyles by all individuals is critical for the prevention of complications from high blood pressure and is an uncontrolled [3]. However, studies show the fact that knowledge on risk factors of hypertension was extremely low, knowledge gaps and misconceptions surrounding hypertension are challenges especially in low-and middle-income countries and having formal education was associated with higher odds of knowledge of hypertension [3-4]. The problem is not an exception for Viet Nam [5-10]. Aiming to create a strong movement worldwide in awareness about the prevention of hypertension and dangerous complications caused by hypertension, the International Association of Hypertension in association with the World Health Organization had an initiative that May 17 every year, since 2005, has been taken as World Hypertension Day. It evidenced in streamlining interventional programmes in order to improve knowledge and prevention of hypertension.

Currently, 528 hypertensive outpatients are being managed by Nghe An Friendship General Hospital Hospital and the average number of hypertensive patients visiting for medical examination is about 15-20 persons. Whether or not the patients' knowledge regarding prevention of complications from hypertension is enough and a formal health education should improve their knowledge regarding prevention of complications from high blood pressure. In order to contribute to the management of hypertension and to limit the complications caused by hypertension to patients, this study was conducted aiming to describe the current knowledge towards prevention hypertensive complications among outpatients managed by Nghe An Friendship General Hospital Hospital in 2021 and to evaluate changes in their knowledge regarding prevention complications from hypertension after a health education intervention.

\section{METHOD}

Study participants were patients with hypertension being treated and managed as outpatients at Medical Examination Department - Nghe An General Friendship Hospital.

Inclusion criteria: patients aged full 18 years or older, had a period of treatment for hypertension at least 1 month or longer at the starting time of the study, participate voluntarily, could answer the interview and had to participate fully in the study's education programs. Exclusion criteria: any patient who was in condition needs to be transferred to be hospitalized; had previously participated in a health education program with similar contents; did not participate enough in the study activities.

In order to achieve the study objectives, the one-group pretest-posttest design was used for this study. Based on the inclusion and exclusion criteria mentioned above 
and convenient sampling method, 89 hypertensive outpatients were recruited in this study during 3 months from February to April 2021.

The education intervention was directly implemented to the patient before they received their prescription and medications. Handouts with illustrations were given to the patient(s) to preview, then the researcher emphasized the main points those are beneficial for preventing complications from hypertension including "compliance with medications", "healthy lifestyle", "regular mornitoring blood pressure", "recognizing and dealing with unusual manifestations" encouraged the patient to ask questions and explained what the patient was not clear about. The education content on prevention of complications due to hypertension was developed based on the recommendations of WHO on prevention of complications for patients with hypertension [11] and Guidelines for Diagnosis and Treatment of Hypertension in Adults 2018 by Viet Nam Heart Association [12].

Data collection was carried out once before, right after the education intervention and one month later by using the questionnaire with Content Validity Index (CVI) of 0.82 and Reliability Coefficient Cronbach's Alpha of 0.72. Beside the demographic information of participating patients, 16 questions were included with 56 answering items, and each correct answer is equal to the score of 1 point. SPSS software was used to analyze the data, simple descriptive statistics such as percentages, mean scores were used to present study results.

Regarding ethical issues, as part of the master's thesis, the study was approved by the NDUN's Scientific Council and the Biomedical Research Ethics Board (IRBVN01012) as well as accepted by Nghe An Provincial General Hospital before conducting the study. All patients clearly understood the study's purpose, their rights and voluntarily signed the consent form before participating in the study. Patients' personal information was confidential, and their responses were only used for the study purpose.

\section{RESULTS}

\section{- Sociodemographic characteristics of the study patients}

Of the 89 participated patients, the number of male patients accounted for $51.7 \%$. The mean age of 89 participants was $71.13 \pm 9.66$ years, the youngest and oldest were respectively 38 and 91 years, and most of them (92.1\%) aged over 60 . The number of retired and educated patients at the secondary level accounted for the highest proportion at $64 \%$ and $41.6 \%$, respectively.

Table 1. Duration of being managed and treated hypertension

\begin{tabular}{|ccc|}
\hline Duration & Number of patients & Percentage \\
\hline$<1$ year & 1 & 1.1 \\
\hline $1-5$ years & 15 & 16.9 \\
\hline$>5$ years & 73 & 82.0 \\
\hline Mean: $6.12 \pm 5.22$ & Min: 0.25 & Max: 20 \\
\hline
\end{tabular}


Up to the time of the study, the study patients had been managed and treated regarding hypertension for an average of $6.12 \pm 5.22$ years, the shortest and longest duration were respectively a quarter of a year and 20 years and the majority of patients (82\%) had been treated for hypertension for more than 5 years.

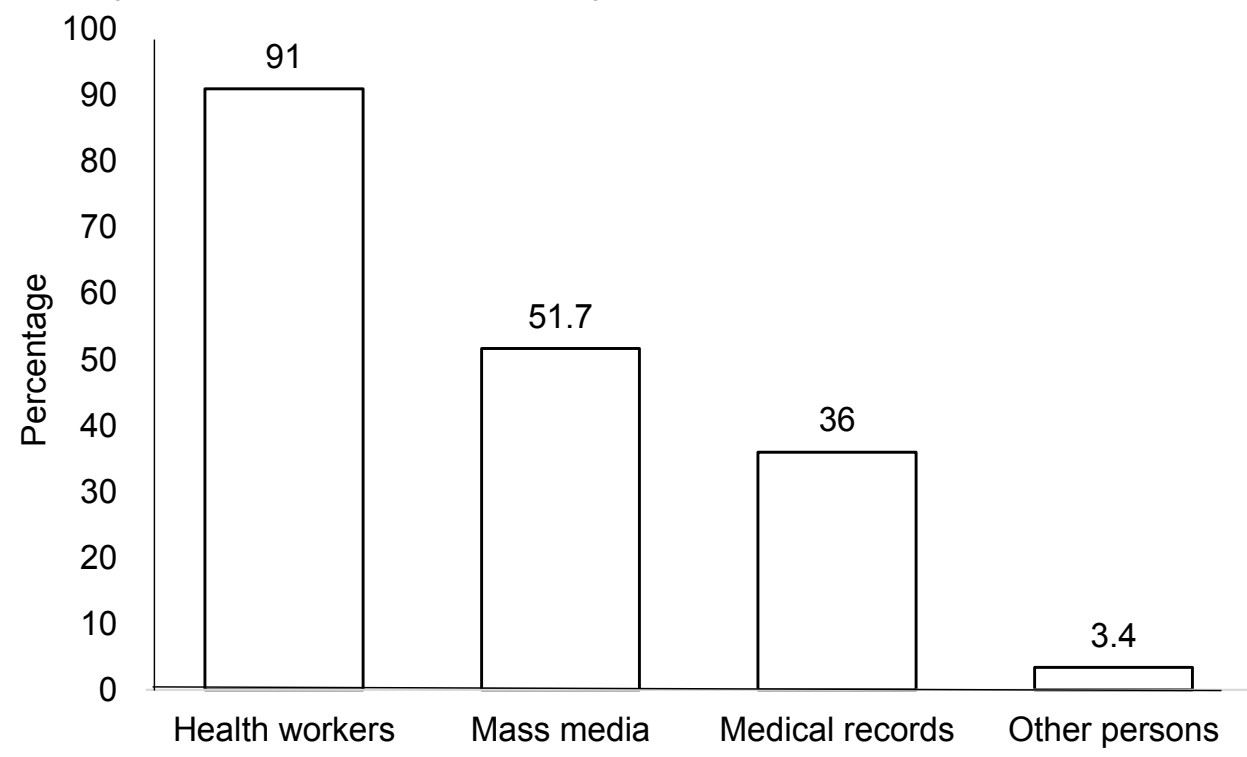

Figure 1. Sources of information regarding hypertension

All study patients responded that they had been provided with information about hypertension through different sources and $91 \%$ of patients answered that the information about hypertension they received was from health workers.

- Patients' knowledge towards prevention hypertensive complications before and after the education

The patients' knowledge participated in the study before and after the educational intervention were analyzed based on the mean score of answering questionnaire then summarized in Table 1 below.

Table 2. Scores by groups of knowledge on prevention of hypertensive complications

\begin{tabular}{|c|c|c|c|c|}
\hline \multirow[b]{2}{*}{ Groups of knowledge } & \multicolumn{3}{|c|}{ Times of measurement } & \multirow{2}{*}{$\begin{array}{l}\text { Band } \\
\text { score }\end{array}$} \\
\hline & $\begin{array}{c}\mathrm{T1} \\
{[\mathrm{Mean} \pm \mathrm{SD}]}\end{array}$ & $\begin{array}{c}\text { T2 } \\
{[\text { Mean } \pm S D]}\end{array}$ & $\begin{array}{c}\text { T3 } \\
{[\text { Mean } \pm S D]}\end{array}$ & \\
\hline $\begin{array}{l}\text { Manifestations of hypertensive } \\
\text { complications }\end{array}$ & $9.99 \pm 2.32$ & $24.65 \pm 3.32$ & $23.66 \pm 4.1$ & $0-25$ \\
\hline Principles of treating high blood pressure & $4.62 \pm 0.83$ & $5.93 \pm 0.03$ & $5.90 \pm 0,37$ & $0-6$ \\
\hline $\begin{array}{l}\text { Manifestations \& treating hypertensive } \\
\text { crisis }\end{array}$ & $2.71 \pm 0.46$ & $5.00 \pm 0.01$ & $4.76 \pm 5.65$ & $0-5$ \\
\hline $\begin{array}{l}\text { Factors increasing the risk of } \\
\text { complications }\end{array}$ & $7.30 \pm 2.04$ & $10.82 \pm 0.58$ & $10.70 \pm 0.63$ & $0-11$ \\
\hline Lifestyle for control high blood pressure & $5.66 \pm 1.01$ & $8.90 \pm 0.30$ & $8.76 \pm 5.37$ & $0-9$ \\
\hline
\end{tabular}


Before the education intervention (T1), all groups of knowledge had unsatisfactory scores. Right after the intervention (T2 and 1 month after the intervention (T3), the scores of patients' knowledge increased significantly.

Table 3. Overall score of knowledge on prevention of hypertensive complications

\begin{tabular}{|c|c|c|c|c|}
\hline \multirow{2}{*}{ Times of measurement } & \multicolumn{3}{|c|}{ Overall score of knowledge } & \multirow{2}{*}{$\begin{array}{c}\mathbf{p} \\
\text { (t-test) }\end{array}$} \\
\hline & Min & $\operatorname{Max}$ & Mean \pm SD & \\
\hline Before the intervention ( $\mathrm{T} 1$ ) & 19 & 37 & $30.28 \pm 4.63$ & \\
\hline Right after the intervention (T2) & 48 & 56 & $55.30 \pm 4.36$ & $p_{2-1}=0.000$ \\
\hline One month after the intervention (T3) & 41 & 55 & $52.89 \pm 5.37$ & $\mathrm{p}_{3-1}=0.000$ \\
\hline
\end{tabular}

Before the intervention, the assessing the overall knowledge of patients regarding prevention of complications due to hypertension revealed the mean score was only 30.28 \pm 4.63 points, more lower than the total 56 points of the scale. And it was seen a significant increase in the scores right after the intervention and one month later at $55.30 \pm 4.36$ points and $52.89 \pm 5.37$ points, respectively ( $p$ values of 0.001 ).

\section{DISCUSSION}

The mean age of 89 hypertensive patients was $71.13 \pm 9.66$ years and the group of patients who were 60 years old accounted for the highest rate with $92.1 \%$. Although our study and the mentioned studies were not epidemiological, these results contribute to confirm the trend of population aging and the prevalence of hypertension in the elderly and posing requirements for elderly health care. Many studies have shown that the older the age, the higher the risk of morbidity and mortality from hypertension-related diseases. The proportion of people with hypertension also increases with age. This is consistent with the WHO's global report (2005), in low-income and middle-income countries, middle-aged adults are more susceptible to chronic diseases, have a longer duration of illness and die earlier than patients in the high-income countries [13].
Before the intervention, all groups of knowledge on prevention of hypertensive complications answered by the study patients received a low score compared to the achievable band scores (Table 2). It would be inappropriate to compare the results of this study with studies regarding similar topics but different scales and scoring in analyzing the results. However, the situation of unsatisfactory knowledge is also reflected by several studies in Viet Nam [6-8] and in other countries [9-10]. On a positive perspective, although it was not reached the maximum score of the 56 -point scale, it must be admitted that before the educational program of this study, the patients participated in the study had possessed a considerable amount of knowledge $(30.28 \pm 4.63$ points as seen in Table 3), equivalent to approximately $54 \%$ of the 56-point scale. It is also undeniable that the length of time in which patients had been managed and treated for hypertension 
(Table 1), multiple sources of information on hypertension, especially from health care workers (Figure 1) contributed to this result before conducting the education program of the study.

Among the groups of knowledge related to the prevention of complications from hypertension, the knowledge about the manifestations of complications due to hypertension before intervention was the most limited group with the Mean \pm SD score of only $9.99 \pm 2.32$ compared to the total 25 points of the band score and this was also the highest improved group right after the intervention and one month after the intervention with the Mean \pm SD scores of $24.65 \pm 3.32$ and $23.66 \pm 4.1$, respectively (Table 2). Fully aware of the possible complications of hypertension and their manifestations plays an important role in a patient's commitment to taking preventive measures in the future. This finding helps to confirm a necessity of assessing before educating the patient, based on that discovering and emphasizing which content a patient is still poor or inadequate in the educational process. This is also one of the notes the study education program of the study followed.

This fact also raises the question of why with the long-term of management and being provided with information about hypertension, knowledge on the prevention of hypertensive complications was not enough and not achieved as expected. Through literature review [3-4], [10-11], it is possible to explain that on the one hand, knowledge is likely to be forgotten over time, on the other hand, studies also pointed the fact that information on hypertension from different sources is inconsistent. Even information provided by medical staff to patients at each follow-up visit is still general, information from mass media is advertising, not sufficient or focussed on the knowledge that a hypertensive patient really needs. In addition, what a hypertensive patient receives is for informational purposes only, not standardized knowledge formally based on a formal educational program [14]. Therefore, the fact of patients' unsatisfactory knowledge on prevention of hypertensive complications shows a need to increase based on a formal and standard basis.

As seen in Tables 2 and 3, right after and one month after the study's education program, the patients' knowledge on prevention of hypertensive complications all went up significantly to $55.30 \pm 4.36$ and $52.89 \pm 5.37$ respectively in comparison with $30.28 \pm 4.63$ before the education. The result of our study together with the positive changes in patients' knowledge seen in some other studies [3], [7], [11] although it is not likely to compare how much level of improvement, but clearly demonstrates the effectiveness of a standardized knowledgebased education program with specific purpose and focused on prevention of complications from hypertension. The study result once again confirms the need to reinforce the knowledge on prevention of possible complications for patients being treated for hypertension and should be carried out as a routine program.

The study also had some limitations such as no control group for comparison and the education intervention was implemented within a group of patients at a hospital, so the result can not be extrapolated. This also did not specifically mention the causes or factors affecting the current status of knowledge to prevent complications due to hypertension of the study subjects before the intervention. 


\section{CONCLUSION}

Knowledge towards preventing complications due to hypertension of the patients participated in the study was unsatisfactory, especially knowledge of hypertensive complications and their manifestations, and there were significant improvements after the study's health education intervention program. The study result once again confirms the need to reinforce the knowledge on prevention of complications for hypertensive patients and should be carried out as a routine program.

\section{REFERENCES}

1. World Health Organization, Hypertension: Key facts. https://www. who.int/news-room/fact-sheets/detail/ hypertension last updated: 25 August 2021.

2. Chobanian AV, Bakris GL, Black $H R$, et al. The seventh report of the joint national committee on prevention, detection, evaluation, and treatment of high blood pressure-the JCN 7 report. J Am Med Association 2003;289:2560-72. doi:10.1001/jama.289.19.2560

3. Ribeiro $C D$ et al. Educational interventions for improving control of blood pressure in patients with hypertension: a systematic review protocol. BMJ open. 2015 Mar 31;5(3):e006583. http://dx.doi. org/10.1136/bmjopen-2014-006583

4. Agyei-Baffour P, Tetteh G, Quansah DY, Boateng D. Prevalence and knowledge of hypertension among people living in rural communities in Ghana: a mixed-method study. Afri Health Sci. 2018;18(4):931-941. doi: 10.4314/ahs.v18i4.12.

5. Nguyen Huu Duc, Pham Van Anh,
Ho Thi Hien. Knowledge and practices of patient adherence in a hypertension club at Bach Mai hospital. Vietnam Journal of Preventive Medicine. 2017;5(27):61-67. (in Vietnamese)

6. Nguyen Thi Thuy and Le Khac Duc. Survey on knowledge of hypertension among hypertensive inpatients at 103 Military Hospital in 2017. Journal of Military Pharmaco - Medicine. 2017; 27(5):29-35. (in Vietnamese)

7. Nguyen Thi Thu Thuy et al. Evaluation of changes in knowledge of adherence to hypertension treatment among the elderly at Bac Ninh Provincial General Hospital in 2018. Journal of Nursing Science. 2018;3(1):15-22. (in Vietnamese)

8. Dinh Thi Thu et al. Knowledge, practice and related factors on prevention of complications from hypertension of outpatients at Quang Ninh Provincial General Hospital in 2018. Journal of Nursing Science. 2019;1(2):19-26. (in Vietnamese)

9. Rijan, $J$ et al. Knowledge, attitude and practice of hypertension among hypertensive patients in a tertiary care teaching hospital, International Journal of Basic \& Clinical Pharmacology. 2019;8(5):1013-1018. http://dx.doi. org/10.18203/2319-2003.ijbcp20191593

10. Chimberengwa, P.T and Naido, M. Knowledge, attitudes and practices related to hypertension among residents of a disadvantaged rural community in Southern Zimbabwe. PLoS One. 2019;14(6): 1-16. https://doi.org/10.1371/journal. pone. 0215500

11. World Health Organization. Complication prevention for patients with hypertension: https:// 
iris.wpro.who.int/bitstream/hand le/10665.1/13561/9789290618034-hypmod7-eng.pdf

12. A non-communicable disease education manual for primary health care professionals and patients. PRO/NCD 2017; ISB 9789290618034 under the CC BY-NC-SA 3.0 IGO licence. https://apps. who.int/iris/handle/10665/254746.

13. Viet Nam Heart Association. Guidelines for Diagnosis and Treatment of Hypertension in Adults 2018. http://vnha.
org.vn/data/Khuyen-Cao-THA-2018.pdf. (in Vietnamese).

14. World Health Organization. Preventing chronic diseases: a vital investment. WHO global report; (2005)." https://apps.who.int/iris/ handle/10665/43314

15. Rober $M$ et al. Prevention and Control of Hypertension. Journal of the American College of Cardiology; Vol. 72, No. 11, 2018: 1278-93. https://doi. org/10.1016/j.jacc.2018.07.008 